https://helda.helsinki.fi

\title{
Identifying the main drivers for the production and maturation of Scots pine tracheids along a temperature gradient
}

\section{Kulmala, Liisa}

2017

Kulmala , L , Read , J , Nöjd , P , Rathgeber , C B K , Cuny , H E , Hollmén , J \& Mäkinen , H 2017 , ' Identifying the main drivers for the production and maturation of Scots pine tracheids pÿalong a temperature gradient ' , Agricultural and Forest Meteorology , vol. 232 , pp. 210224 . https://doi.org/10.1016/j.agrformet.2016.08.012

http://hdl.handle.net/10138/178326

https://doi.org/10.1016/j.agrformet.2016.08.012

acceptedVersion

Downloaded from Helda, University of Helsinki institutional repository.

This is an electronic reprint of the original article.

This reprint may differ from the original in pagination and typographic detail.

Please cite the original version. 


\title{
Identifying the main drivers for the production and maturation of Scots pine tracheids along a temperature gradient
}

\author{
Liisa Kulmala ${ }^{\mathrm{c}, 1,2}$, Jesse Read $^{\mathrm{a}, \mathrm{b}, 2}$, Pekka Nöjd $^{\mathrm{d}}$, Cyrille. B. K. Rathgeber ${ }^{\mathrm{e}}$, Henri E. \\ Cuny $^{\mathrm{f}}$, Jaakko Hollmén ${ }^{\mathrm{a}}$, Harri Mäkinen ${ }^{\mathrm{d}}$ \\ ${ }^{a}$ Department of Computer Science, Aalto University and HIIT, P.O. Box 15400, FI-00076 Aalto, \\ Helsinki, Finland \\ ${ }^{b}$ Computer Science and Networks Dept., Télécom ParisTech, 46 Rue de Barrault, 75013 Paris, France \\ ${ }^{c}$ Department of Forest Sciences, University of Helsinki, P.O. Box 27, FI-00014 University of Helsinki, \\ Finland \\ ${ }^{d}$ Natural Resources Institute Finland, Jokiniemenkuja 1, FI-01370, Vantaa, Finland \\ ${ }^{e}$ LERFOB, INRA, AgroParisTech, UMR 1092 LERFOB, F-54000 Nancy, France \\ ${ }^{f}$ Swiss Federal Research Institute WSL, Zürcherstrasse 111, CH-8903 Birmensdorf, Switzerland
}

\section{${ }_{14}$ Abstract}

Even though studies monitoring the phenology and seasonal dynamics of the wood formation have accumulated for several conifer species across the Northern Hemisphere, the environmental control of tracheid production and differentiation is still fragmentary. With microcore and environmental data from six stands in Finland and France, we built auto-calibrated data-driven black box models for analyzing the most important factors controlling the tracheid production and maturation in Scots pine stem. In the best models, estimation was accurate to within a fraction of a tracheid per week. We compared the relative results of models built using different predictors, and found that the rate of tracheid production was partly regular but current and previous air temperature had influence on the sites in the middle of the temperature range and photosynthetic production in the coldest ones. The rate of mature cell production was more difficult to relate to the predictors but recent photosynthetic production was included in all successful models.

Keywords: micro-core measurements; xylogenesis; diameter growth; gross primary production; black box modeling; predictive models 


\section{Introduction}

${ }_{41}$ mean air and soil temperature and tracheid formation in Jack pine (Pinus banksiana

42 L.) stem. Oberhuber et al. (2014) found a negative relationship between vapour pres-

\footnotetext{
${ }^{1}$ Corresponding author, +358 2941 57981, liisa.kulmala@helsinki.fi

${ }^{2}$ Equal collaboration of the first two authors
} 
sure deficit (VPD) and tree ring increment indicating that high VPD and the resulting

${ }_{44}$ high evaporative demand reduces turgor pressure in cells, as well as cell division and

45 enlargement. Also in drought-prone areas, water deficits in late spring and summer play

46 a critical role in the onset of xylogenesis and xylem cell production (Kalliokoski et al.,

47 2012; Ren et al., 2015; Oberhuber et al., 2014; Lempereur et al., 2015). The role of dif-

48 ferent environmental factors controlling intra-annual growth dynamics most likely vary

49 depending on growing environment but this is still not clearly understood.

50 Photosynthesis provides material for the growth and wood formation. A positive 51 connection between annual ring width and net ecosystem productivity (NEP) or gross ${ }_{52}$ primary production (GPP) has been reported (Ohtsuka et al., 2009; Babst et al., 2014; 53 Gea-Izquierdo et al., 2014; Schiestl-Aalto et al., 2015). On the other hand, Delpierre et al. 54 (2016a) demonstrated that soil water and VPD are more important variables than carbon 55 fluxes in determining weekly rates of wood formation in a temperate Oak. Zweifel et al. 56 (2010) found a close relationship between stem radius changes and monthly and half57 hourly NEP and monthly GPP but their study was based on stem radius measurements, 58 which also include the swelling and shrinking of stems due to changes in water balance ${ }_{59}$ as well as the growth and regeneration of the phloem.

A detailed view on the importance of different environmental factors and photosynthetic production may help us perceive the effects of changing climate on secondary growth and the acclimation capacity of trees. The aim of this study is to examine which climatic and ecophysiological factors explain best the intra-annual dynamics of cell production and maturation in Scots pines (Pinus sylvestris L.) in different environments. Thus, we selected six Scots pine stands (three in Finland along a latitudinal gradient and three in France along an altitudinal gradient) from which we have three to four years (depending on the stand) of wood formation monitoring and environmental data, including measured daily average of temperature, radiation, and precipitation, air humidity as VPD, and modelled soil moisture and GPP. The total number of tracheids at different stages of cell differentiation and the number of mature tracheids (i.e., tracheids that had 
${ }_{95}$ Cuny et al. (2015).

${ }_{96} \quad$ The air temperature $(\mathrm{T})$, precipitation $(\mathrm{P})$ and air relative humidity $(\mathrm{RH})$ were mea${ }_{97}$ sured at each site except for Ruotsinkylä (site 3). Solar radiation (I) were measured at 


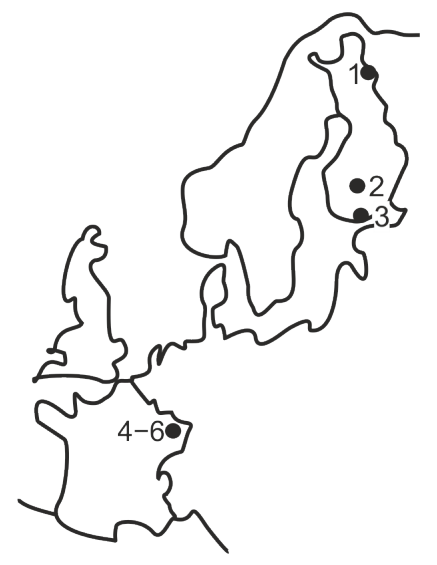

Figure 1: Site map.

SMEARI and SMEARII whereas the solar radiation at the French sites was measured at a nearby meteorological station and used for all the sites. For Ruotsinkylä, T, RH, P and I were attained from the nearby $(5 \mathrm{~km})$ weather station maintained by the Finnish Meteorological Institute. Special weather events such as drought, heavy winds etc. were not recorded in the study sites during the measured years.

03

Vapour Pressure Deficit ( $V P D, P a)$ was computed as

$$
V=v-R H \frac{v}{100},
$$

where $R H(\%)$ is relative humidity, and $v(\mathrm{~Pa})$ the saturated water pressure,

$$
v=e^{77.345-7235.42 / T-8.2 \log (T)+5.7113 T / 1000}
$$

where temperature $(T)$ is in Kelvins.

\subsection{GPP estimates}

We predicted daily gross primary production (GPP) and soil water content (S) using an empirical model PRELES (Peltoniemi et al., 2015). The GPP section of the model has been validated using measurements from seven pine and spruce stands located between latitudes $44^{\circ} 27^{\prime}$ and $67^{\circ} 22^{\prime}$ (Mäkelä et al., 2008). In the model, soil water content (S) is 
Table 1: Sites, and their mean annual temperature $\left(\mathrm{T},{ }^{\circ} \mathrm{C}\right)$, with mean average temperatures from the coldest and the warmest month in parenthesis, precipitation $(\mathrm{P}, \mathrm{mm} /$ year $)$, mean VPD $(\mathrm{kPa})$ with mean average VPD of the month with highest VPD in parenthesis, altitude $(\mathrm{m})$, latitude $(\mathrm{N})$, mean tree age (years), height $(\mathrm{H}, \mathrm{m})$, diameter at $1.3 \mathrm{~m}(\mathrm{D}, \mathrm{cm})$, number of stems $\left(\mathrm{N}, h a^{-1}\right)$, and data range. The first three sites are in Finland, and the other three sites are in France.

\begin{tabular}{llllllllllll}
\hline & name & $\mathrm{T}(\min : \mathrm{max})$ & $\mathrm{P}$ & $\mathrm{VPD}$ & alt. & lat. & age & $\mathrm{H}$ & $\mathrm{D}$ & $\mathrm{N}$ & data range \\
\hline 1 & SMEARI & $0.8(-11: 12)$ & 580 & $0.16(0.44)$ & 390 & $67^{\circ} 5$ & 90 & 9 & 14 & 770 & $2007-2009$ \\
2 & SMEARII & $4.3(-8: 17)$ & 590 & $0.31(0.75)$ & 181 & $61^{\circ} 9$ & 46 & 16 & 18 & 755 & $2007-2010$ \\
3 & Ruotsinkylä & $5.9(-9: 19)$ & 703 & $0.28(0.74)$ & 60 & $60^{\circ} 2$ & 38 & 18 & 18 & 1002 & $2007-2010$ \\
4 & Grandfontaine & $8.6(1: 16)$ & 1520 & $0.24(0.45)$ & 650 & $48^{\circ} 6$ & 119 & 27 & 53 & 431 & $2007-2009$ \\
5 & Abreschviller & $9.2(1: 17)$ & 1190 & $0.22(0.39)$ & 430 & $48^{\circ} 6$ & 162 & 36 & 33 & 253 & $2007-2009$ \\
6 & Walscheid & $10(1: 19)$ & 900 & $0.36(0.68)$ & 370 & $48^{\circ} 5$ & 95 & 31 & 52 & 189 & $2007-2010$ \\
\hline
\end{tabular}

111 calculated using a bucket model using precipitation as an inflow and evapotranspiration

112 and runoff as outflows. We simplified the calculation of evapotranspiration (E) as follows:

$$
E=\beta_{E} G \frac{V}{V^{\kappa_{E}}}+\alpha_{E}\left(1-f_{A P A R}\right) P A R f_{W, E}
$$

113

where $\mathrm{G}$ is GPP, $\mathrm{V}$ is $V \mathrm{PD}, P A R$ is the daily sum of photosynthetic photon flux density, $\beta_{E}, \kappa_{E}, \alpha_{E}$, and $f_{A P A R}$ parameters and $f_{W, E}$ a soil water modifier as in Peltoniemi et al. (2015). The chosen soil water model is parametrized at site 2 leading there to similar results with the original model but with less complexity.

Briefly, PRELES predicts the GPP as a product of 1) potential daily light use efficiency (LUE), 2) fraction of absorbed photosynthetically active radiation $\left(f_{\text {APAR }}\right)$ describing the photosynthesising leaf area, 3) photosynthetically active radiation (PAR), and 4) modifying factors that in suitable conditions result in 1 and in unsuitable conditions to less than one decreasing the potential GPP. The modifying factors are four independent functions with PAR, temperature history, VPD and relative extractable soil water $(\mathrm{REW})$ as determinants. We used the same model parameters for each site (Table A.7) using the values that Peltoniemi et al. (2015) have estimated and tested for SMEARII (site 2). The leaf area increases in early season and decreases in late season but we treated it as a constant since the changes in it are partly reflected in the factor of temperature history. The acceptable performance against empirical data (Mäkelä et al., 
2008) allows such simplification to decrease the complexity of the model. Since we are not interested in the overall level of GPP in the stand but the interannual variation in the studied Scots pines, we did not include the exact stand characteristics in the model (e.g. maximum LAI). Thus, we treated GPP as a relative value describing the daily photosynthesis of Scots pines during a growing season inside a stand.

\subsection{Sample Collection and Preprocessing}

Xylem formation in stems was monitored by repeatedly collecting microcores at a height of $1.3 \mathrm{~m}$. They were collected from each site from four to five randomly selected dominant trees once or twice a week in spring and early summer, and once a week in late summer and autumn. The first samples were taken between early April and mid-May and the sampling continued to mid-September in Finland and to late November in France. From the images taken of the current-year ring samples, the number and diameters of tracheids in different tracheid formation phases were measured along one representative tracheid row. The details of the sampling and the laboratory analyses are described by Kalliokoski et al. (2012), Jyske et al. (2014) and Cuny et al. (2012, 2014). In order to study the rate of differentiating tracheid production (RDTP) and the rate of mature cell production (RMTP), we recorded both the total number of tracheids (i.e., the sum of tracheids in all formation phases) and the mature tracheids (i.e., tracheids which have completed the cell formation and entered the mature stage).

Noise is unavoidable in this kind of data, and we took a number of steps to produce reasonable rates for RDTP and RMTP from the measurements. The procedure is exemplified in Figure 2. As a first step, we considered a time scale of weeks, rather than days; averaging by week provides at least one measurement for most weeks during the growing season. We considered week $t=1$ of the year as the first to seventh day inclusive, and so on. In the cases where measurements for more than one tree were available, we used the average number of cells of all trees for each week, since we were interested in the relative differences in the rates among particular sites rather than individual trees. We assume zero new tracheids on all weeks prior to the first measurement and posterior to 
Table 2: Sites and the number of missing values which are smoothed over.All site-years not appearing had complete data time series.

\begin{tabular}{lll}
\hline & Site & Year (Num. Missing) \\
\hline 1 & SMEARI & $2008(1), 2009(6)$ \\
2 & SMEARII & $2007(11)$ \\
4 & Grandfontaine & $2007(5), 2008(4), 2009(6)$ \\
5 & Abreschviller & $2007(9), 2008(1), 2009(1)$ \\
6 & Walscheid & $2007(9), 2008(1), 2009(5)$ \\
\hline
\end{tabular}

Table 3: Summary of notation. $\mathbf{x}_{t}$ and $y_{t}$ can be considered general inputs and output, respectively.

\begin{tabular}{lll}
\hline variable & range & symbol \\
\hline$t$ & $\in\{1, \ldots, 52\}$ & time index (week number) \\
$\mathbf{x}_{t}=\left[x_{1}, \ldots, x_{p}\right]$ & $\in \mathbb{R}^{p}$ & data input for week $t$, of $p$ variables \\
$y_{t}$ & $\in \mathbb{R}$ & growth at week $t$ (number of cells) \\
$\hat{y}_{t}$ & $\in \mathbb{R}$ & estimated growth given input, with black box model \\
$T(t)$ & $\in \mathbb{R}$ & avg. air temperature week $t$ \\
\hline
\end{tabular}

the last measurement of each year (i.e., outside of the growing season). For all other weeks (i.e., during the growing season), we plugged in a value from a linear fit between the surrounding values. For example, if $\tilde{y}_{t}$ is the average number of measured tracheids at week $t$, and we have $\tilde{y}_{23}=12$ and $\tilde{y}_{26}=18$ but weeks 24 and 25 are missing, then we plugged in values $\tilde{y}_{24}=14$ and $\tilde{y}_{25}=16$. The number of values affected by this operation is signaled in Table 2. We smoothed these measurements with a weighted average,

$$
\bar{y}_{t} \leftarrow 0.05 \tilde{y}_{t-2}+0.25 \tilde{y}_{t-1}+0.40 \tilde{y}_{t}+0.25 \tilde{y}_{t+1}+0.05 \tilde{y}_{t+2}
$$

and furthermore capped this value such that $\bar{y}_{t} \leftarrow \max \left(\bar{y}_{t}, \bar{y}_{t-1}\right)$. This ensured that RDTP and RMTP are never negative. Since we already smoothed (averaged) by week as an initial step, more advanced smoothing was not needed.

In the final step, we converted the running cumulative sum of total number of cells and the number of mature cells into a rate (of new tracheids/week); as we were primarily interested in modelling the week-to-week rate of tracheid production, indicated henceforth as $y_{t}$. 


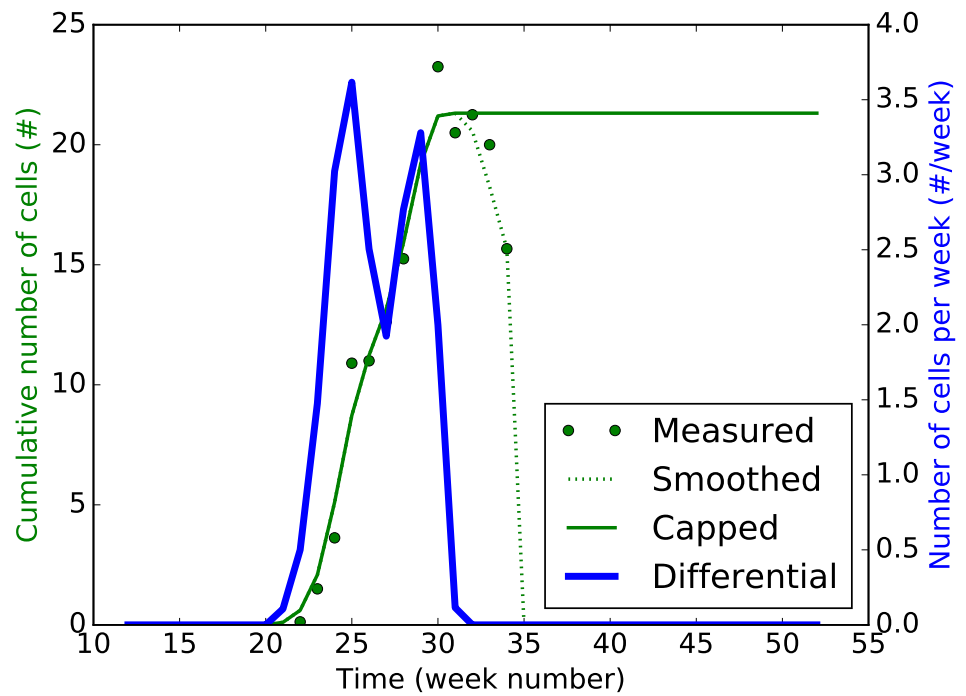

Figure 2: Example of preprocessing: for SMEARI in the year 2007. Raw tracheid-counts (total) have been averaged by week, smoothed, capped to prevent negative growth, and then a differential is taken to represent week-by-week growth (RDTP).

\subsection{Black Box Models}

A black box refers to a data driven model where inputs and outputs are the focus, as opposed to the internal mechanism. Thus, the mechanism of mapping inputs to outputs is not designed by domain knowledge, but rather constructed automatically from data. The chosen algorithm is of a lesser importance than its predictive performance, and the focus is on interpreting relative results.

Instances of explanatory variables (i.e., inputs), each associated with a target variable (i.e., output), are used as training data to build a model. In our case, input attributes were environmental data and the week number, and the target variable was the rate of tracheid production/maturation (RDTP/RMTP) for a given week; See Table 3. These instances were fed into an off-the-shelf learner along with the target variable, and a model was built. With this model, the target RDTP and RMTP (output) for any particular week can be estimated automatically from environmental records on and prior to this week (input). 
After an empirical trial of some popular learning algorithms, we chose ridge regression (Hastie et al., 2001) to use as a black box. This kind of model extends ordinary least squares regression with a penalty regularization term on the coefficients to avoid overfitting (i.e., avoid excessively large coefficients), such that the error function for MSE to be minimized is

$$
\begin{aligned}
E(\boldsymbol{\beta}) & =\sum_{t=1}^{52}\left(\boldsymbol{\beta}^{\top} \mathbf{x}_{t}-y_{t}\right)^{2}+\frac{1}{\lambda} \boldsymbol{\beta}^{\top} \boldsymbol{\beta} \\
& =\sum_{t=1}^{52}\left(\hat{y}_{t}-y_{t}\right)^{2}+\frac{1}{\lambda} \boldsymbol{\beta}^{\top} \boldsymbol{\beta}
\end{aligned}
$$

where $\boldsymbol{\beta}$ is the vector of coefficients, and $\lambda$ is a parameter on the penalty, that is automatically tuned via internal cross validation. Essentially, it is MSE plus a penalty term. We used the Python programming language, and in particular the scikit learn package ${ }^{3}$ for the ridge regression implementation. Although we found that ridge regression provided good results on our data, any predictive regression model can be used (e.g., ordinary linear regression, decision tree regressors, $k$-nearest neighbours).

\subsection{Variables for the Black Box}

Given an algorithm, and a chosen output variable (RDTP and RMTP in our case) the remaining task is the configuration of input, i.e., choosing and/or creating transformations of explanatory variables. From a knowledge-blind point of view, all predictive power will come from some time horizon of the input (environmental measurements) up to the current week $t$; as well as the week number $t$. In other words, the week number $t$, and a time horizon of environmental measurements is provided to the black box, to output an estimate at week $t$.

Regarding the length of time horizon, we conducted a pilot study on the effect of different horizons on predictive accuracy based on models of multiple environmental

${ }^{3}$ http://scikit-learn.org 


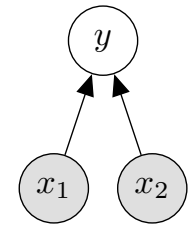

(a) Simple linear model

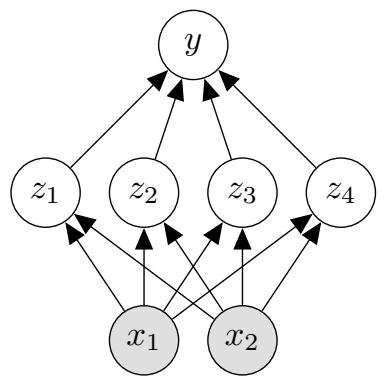

(b) Model with middle layer

Figure 3: Figure 3a represents a simple linear model in graphical form, and Figure 3b shows the general concept of an inner layer to provide non-linearity. This layer $\left(z_{1}, \ldots, z_{4}\right)$ can either be viewed as part of a (non-linear) black box, or as a different configuration of the input to a (linear) black box.

measurements, and found that in general, accuracy improved for most sites up until including about 10 weeks of environmental history. For other sites (whose model did not benefit from such a long horizon) the longer time horizon still did no harm, since an appropriately regularized black box model (as ridge regression that we chose) learns coefficients close (or at) zero for the variables corresponding to the oldest weeks. Therefore we used a time horizon of 10 weeks for all models. In practice this means that the model makes an estimation of growth (in number of tracheids) at the current week, as a function of environmental measurements at the present week and all measurements of the prior 10 weeks.

A linear model of input is often insufficient for most predictive variables. For example, the week number $t$ correlates to low/zero RDTP/RMTP for both low values (beginning of the year) and high values (end of the year). Similarly, although basic temperature variables such as the sum and average can be modeled by a simple linear combination of variables, the relationship of temperature to tracheid formation is in practice non-linear. A well-known way to allow non-linearity in statistical models is via basis functions, for example a polynomial transformation Hastie et al. (2001).

The basis functions can be viewed as an inner layer that provides non-linear predictive power (Figure 3). This strategy is used by a plethora of approaches including neural networks and latent variable models (Hastie et al., 2001). 
As well as automatic/blind variable transforms, we looked at two expert functions. First, as a short term response to environmental drivers, we used

$$
D(T(t) ; c)=1_{T(t)>c}\left[\frac{1}{1+\exp (-0.1 T(t))}\right]
$$

as inspired by Schiestl-Aalto et al. (2015), except that we did not sum cumulatively. Essentially this function acts as switch which yields zero whenever the average temperature is at or below a threshold $c^{\circ} C$, and otherwise returns a value between 0 and 1 representing the weekly temperature (closer to 1 represents higher temperature, Figure 4). We set parameters $c=\{0,5,10\}$, i.e., we include three variables, $D(T(t) ; 0), D(T(t) ; 5), D(T(t) ; 10)$, in the same model. Unlike Schiestl-Aalto et al. (2015) we average by week (rather than by day) and consider the tracheid production/maturation rate rather than cumulative number. Note that $D=0$ corresponds to zero change in a cumulative temperature sum. Including $D$ over a time horizon in the model (as we did) offers approximate predictive power to a cumulative sum inside $D$ itself (depending on the length of the time horizon).

Secondly, we used a timing variable also inspired from (Schiestl-Aalto et al., 2015):

$$
\begin{aligned}
O\left(t ; t_{o}, o, T(\ldots, t)\right) & =\max \left(0,4 \frac{\left[o \sqrt{t^{\prime}}-t^{\prime}\right]}{o^{2}}\right) \\
t^{\prime} & =\max \left(0, t-t_{o}, t-\min _{t}(T(t)>0)\right)
\end{aligned}
$$

where $t^{\prime}$ begins counting at week number $t_{o}$ unless the temperature is still below zero, in which case it begins on the first week of average temperature above $0^{\circ} \mathrm{C}$. In other words: the signal of this function begins (raises above 0) at the first instance when the week number is at least $t_{o}$ and temperature is above 0 . It also yields a value $O \in$ $[0,1]$ increasing sharply at first and decreasing gradually after that (Figure 4$)$. There is empirical evidence suggesting that trees in the cold northern Finland start to grow at lower temperatures (Jyske et al., 2014). Therefore, to attain a reasonable fit, we set $o=$ $\{4.5,5.0\}$ for Finnish sites and $o=\{5.0,6.0\}$ for French sites; and $t_{o}=\{11,12,13,14\}$. 

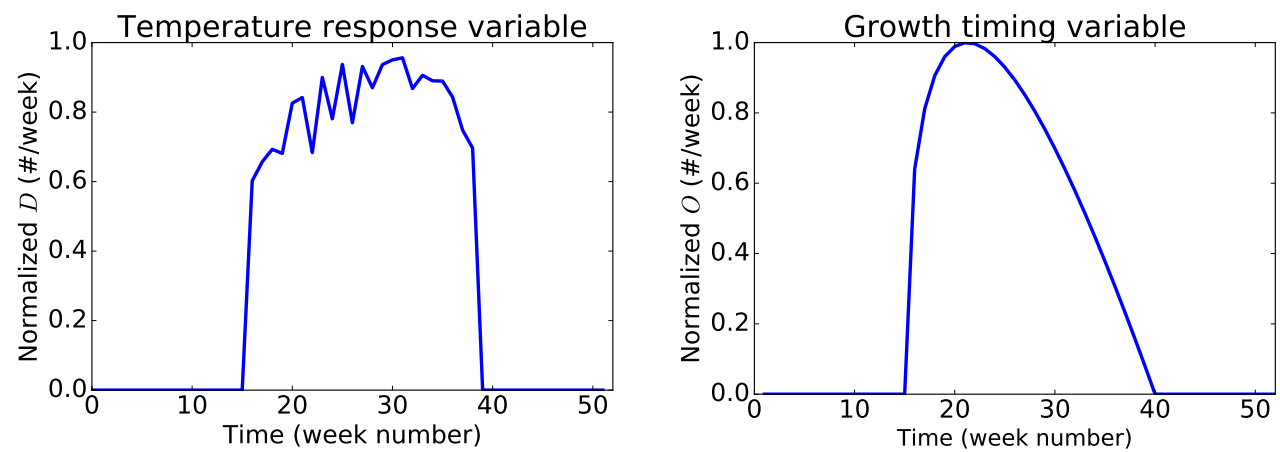

Figure 4: Illustrations of the shapes of short-term response to temperature $(D)$ and growth timing with $(O)$. The horizontal axis is time (in weeks). Note that for purposes of illustration we have chosen the temperature data from Site 1 (SMEARI) during 2007.

In other words, we included a total of eight $O$ variables per model.

Therefore, rather than manual calibration of a single function, we used several different calibrations which the black box automatically calibrates with additional parameters (e.g., coefficients). Therefore in-depth domain knowledge is not required and the model is still heavily data driven, even though in this particular case, the functions we used were derived from experts. This could be called a 'grey box'.

Lupi et al. (2010) show that the timing of cell maturation (hence possibly the rate of mature tracheid production) is dependent on the number of tracheids produced earlier in the season. Including the measured number of tracheids early in the season in the model detracts from the applicability of a model, since it requires measurements in order to run the model. Instead, we also consider as a variable the predicted number of tracheids over the time horizon as an additional variable for predicting the number of mature tracheids $($ denoted $P)$.

An overview of variables used in the model is given in Figure 5. In the results we experiment with different combinations of variables, for example (D.O.G $)^{5}$ means that we used $D$ and $O$ and $G$ variables, via polynomial transformation of degree 5 . 


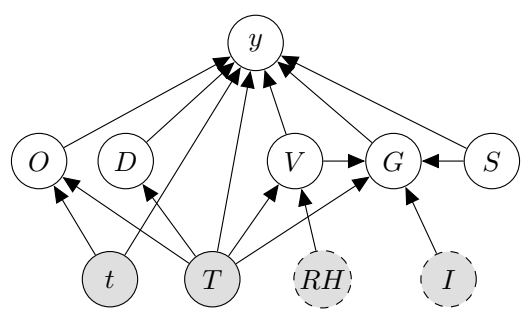

Figure 5: Model variables. Shaded nodes represent environmental measurements (temperature $T$, relative humidity $R H$, and solar radiation $I$ ) and the week number $(t)$. Nodes with a dashed outline were used only indirectly. Second-level nodes represent higher-level variables $(V=V P D, G=G P P, S=$ soil moisture, the growth-timing variable $O$, and the short term response to environmental drivers $D$ ). The direction of arrows represent flow of information, e.g., the week number and mean weekly temperature were used in the calculation of growth timing factor $O$. For brevity, we excluded nodes and connections used in the estimation of the soil moisture variable, the polynomial transformations, and the growthprediction variable used only for prediction of mature tracheids $(P)$.

\subsection{Evaluation}

As we built models separately for each site, we also evaluated them on a per-site basis, in order to compare and contrast the predictive power of different inputs in different temperature environments. For a given site, and a given year, we scored a model with the mean squared error (MSE).

We built the models on data from all available years (52 data points per year) except the final year, which we held aside for testing the model. We repeated this procedure but instead holding aside the penultimate year, and then again for the ante-penultimate year of measurements for evaluation. The results of the three years were then averaged together. This procedure is similar to hold-one-out cross validation (except that the number of years varies per site).

\subsection{Interpretation: Opening the Black Box}

The large number of variables created in the black box corresponds to an equally large number of coefficients in the regression model that we used, and makes it difficult to analyze the model. For the purpose of interpretation, we additionally run the models with decision-tree regressors. These are powerful non-linear models, that are relatively easy to interpret (Hastie et al., 2001). On account of the inherent non-linearity, there was no need for basis transformations, which reduces the number of variables. Furthermore, 
in this case since the intention is for interpretation rather than accuracy evaluation, we trained the models on all available data for each site. In each case, we selected the best set of predictors (as determined by the standard black-box evaluation) for the model, with a minimum of 10 samples per leaf and a maximum depth of 5 , to enforce a parsimonious (more easily interpretable) model.

The decision-tree models can be interpreted as follows. First note that for clarity and simplicity we have simply denoted the six different parameterizations of the growthtiming function as $a, \ldots, f$ (refer to Eq. (8) for the full form). For example, $O(a)[-3]$ in Figure A.8a is short-form for $O(t-3 ; 5,11, T(\ldots, t-3))$. If this function produces a value greater than 0.85 , and (passing then to the right branch) the value of $D(T(t-9) ; 0)$ is not more than 0.57 (branching to the left), then growth at the current week $t$ is projected to be 2.46 cells. The value 2.46 was average growth of the 11 different weeks that met this criterion over all three years of data. When building the model, each criterion is chosen greedily based on the MSE. An MSE values in the diagrams refer to the error under each particular criteria. Exactly as in Table A.6, this MSE value may be generally higher for some sites, such as Site 3 Ruotsinkylä. Finally, note that we have de-standardized data for interpretation, thus $T[-1] \leq 10.06$ (for example, Figure A.9a) actually refers to the temperature one week ago not being more than $10.06^{\circ} \mathrm{C}$ (therefore, it makes sense that for this site, growth should be coming to a stop, and hence the left side showing lower values)

\section{Results}

\subsection{The Rate of Differentiating Tracheid Production (RDTP)}

The timing of growth variable $(O$, Eq. (8)) showed in general the lowest MSE values and had the best average rank explaining the rate of new tracheid production (RDTP, Table 4a) when all available variables were tested as input separately. However, it was the best factor only at the two warmest sites while elsewhere mainly air temperature as 
a polynomial function or as a growth-response variable $(D$, Eq. (7)) was the best single predictor for RDTP.

When different variables were combined to predict RDTP, the combination of week number and temperature resulted in the best average rank (Table 5a). However, $O$ alone resulted in lower MSE value (Table A.6a,c) than any of the combinations at the two warmest sites $(5,6)$ where it mostly succeeded to predict the onset and cessation of RDTP but failed to predict the observed dynamics in-between with satisfactory manner (Figure 6e,f).

At the sites 3 and 4, the lowest MSE values resulted from models including either temperature as the only variable or combined with the week number $(t)$ (Table 5a, Table A.6a,c). However, the inclusion of $t$ lowered MSE value only a little in site 3 (Table A.6) and it was pruned from the most topmost variables in the decision-tree (Figure A.8c,Figure A.9a) indicating that at these sites $(3,4)$, the observed changes in RDTP were mainly connected to the changes in air temperature. The models with lowest MSE values for these sites succeeded to predict some of the intra-annual dynamics of RDTP (Figure 6c,d). The decision tree analysis revealed that with high temperatures (i.e., in the middle of the growing season), current temperature was the most important variable but also temperatures from 9-10 weeks earlier were important for estimation (Figure A.8c,Figure A.9a).

The best RDTP models at the coldest sites $(1,2)$ included $O$ and GPP (Table 5a). For site 2, the decision tree models revealed that with small $O$ values current GPP mattered whereas GPP earlier in the season seemed to be important with higher $O$ values (Figure A.8b). In addition to $O$ and GPP, temperature in the form of $D$ and VPD were included in the best model for the coldest site (1). The decision tree model showed that $O$ was again the most important variable while the timing of most important temperatures (as $D$ ) occurred 8-9 weeks earlier the actual growth. GPP and VPD were pruned away, indicating their lesser importance (Figure A.8a). 


\subsection{The Rate of Mature Tracheid Production (RMTP)}

Overall, the expert timing of growth variable $(O$, Eq. (8)) was the best single variable to predict RMTP even it was not the best one at any of the sites (Table 4b). The week number was the best single variable at the two warmest sites $(5,6)$. In the chilliest site (1), $D$ was the best single variable. GPP was the best predictor for the chilliest French and warmest Finnish sites (sites 2-4).

The combination of $O$ and GPP resulted in the best average rank when predicting RMTP (Table 5b). However, week number (t) alone at the warmest site 6 and $D$ at the chilliest site 1 showed the lowest MSE values for RMTP (Table A.6b,d) but the model fits were poor (Figure A.7a,f). At all other sites, GPP was included in the best models to predict RMTP. In addition, the inclusion of $O$ and $\mathrm{T}$ at site $5, \mathrm{~T}$ at site 4 , and $O$ at site 2 improved the model performance (Table 5b, Table A.6d). In general, the model fits for RMTP (Figure A.7) were poorer as for RDTP (Figure 6). Inclusion of the predicted number of cells did not result to lower MSE values at any site even it resulted into a high rank at sites 3 and 4 (Table $5 \mathrm{~b})$.

The detailed view on model behaviour at site 2 illustrated that with low $O$ values, previous GPP mattered whereas with higher $O$ values, the important GPP rised from

four weeks earlier (Figure A.10b). At the site 4, GPP was most important but if it had been high, then also T was involved (Figure A.11a). At site 5, GPP was most important in small $O$ values whereas in high $O$, temperature was more important than GPP. The decision tree analysis revealed that overall, the most important $O$ values have occurred already 4-10 weeks earlier in the sites where it was included in the best models.

\section{Discussion}

We applied fundamental computational methods for gaining new insights into relationships between intra-annual dynamics of tree growth and environment. We built black box models on several years of environmental measurements associated with rates of tracheid production and maturation in Scots pine stems, for six sites spread along an 
Table 4: Results with individual variables: week of the year $(t)$, air temperature (T), soil moisture (S), $\operatorname{VPD}(\mathrm{V}), \operatorname{GPP}(\mathrm{G})$ and the expert variables of environmental drivers $D$, and growth timing $O$. A superscript indicates the degree of polynomial on the variable, e.g., $(T)^{5}$ implies that variables $T, T^{2}, \ldots, T^{5}$ were used. The per-site ranking of each of the seven black box models is shown with respect to the other models (only the top 3 rankings are displayed for clarity). This ranking is based on an average error over three years (Table A.6).

(a) Ranks - Rate of tracheid production (RDTP)

\begin{tabular}{lrrrrrrr}
\hline Dataset & $(t)^{5}$ & $(T)^{5}$ & $(S)^{5}$ & $(V)^{5}$ & $(G)^{5}$ & $D$ & $O$ \\
\hline SMEARI & & & & & 2 & $\mathbf{1}$ & 3 \\
SMEARII & $\mathbf{1}$ & 3 & & & & & 2 \\
Ruotsinkylä & 2 & $\mathbf{1}$ & & & & & 3 \\
Grandfontaine & & $\mathbf{1}$ & & & & 3 \\
Abreschviller & 2 & 3 & & & & & $\mathbf{1}$ \\
Walscheid & 2 & 3 & & & & & $\mathbf{1}$ \\
\hline avg rank & 2.67 & 2.50 & 7.00 & 5.83 & 4.33 & 3.50 & 2.17 \\
\hline
\end{tabular}

(b) Ranks - Rate of mature tracheid production (RMTP)

\begin{tabular}{lrrrrrrr}
\hline Dataset & $(t)^{5}$ & $(T)^{5}$ & $(S)^{5}$ & $(V)^{5}$ & $(G)^{5}$ & $D$ & $O$ \\
\hline SMEARI & & 3 & & & & $\mathbf{1}$ & 2 \\
SMEARII & & & & & $\mathbf{1}$ & 2 & 3 \\
Ruotsinkylä & 2 & & & & $\mathbf{1}$ & & 3 \\
Grandfontaine & & & & & $\mathbf{1}$ & 2 & 3 \\
Abreschviller & $\mathbf{1}$ & 3 & & & & & 2 \\
Walscheid & $\mathbf{1}$ & & & & 3 & & 2 \\
\hline avg rank & 2.67 & 4.50 & 6.50 & 5.67 & 3.00 & 3.17 & 2.50 \\
\hline
\end{tabular}




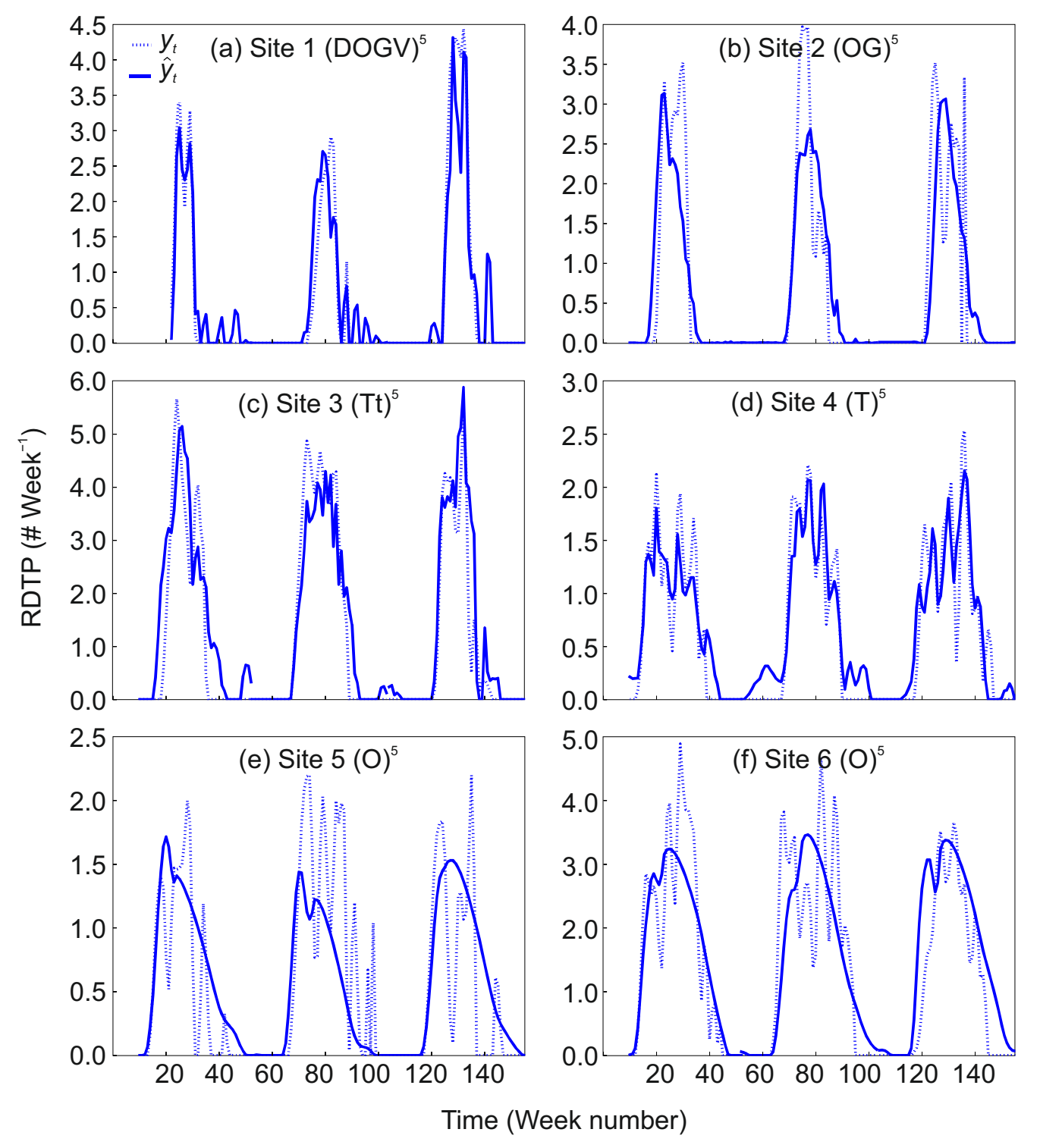

Figure 6: Measured $(y)$ and estimated $\left(\hat{y}_{t}\right)$ total new tracheids formed per week (vertical axis) of the black box model for all years tested. The variables of the model were those which obtained the top rank in Table 5 (each site modeled separately). 
Table 5: Results with combinations of variables, calculated and displayed similarly to Table 4 . Note that predicted number of tracheids $P$ is only used as a variable for number of mature tracheids (in $(P . T . G)^{5}$ $5 \mathrm{~b})$; in $5 \mathrm{a}$ we instead include the (D.O.G. $)^{5}$ variable set.

(a) Ranks - Rate of tracheid production (RDTP)

\begin{tabular}{lrrrrrr}
\hline Dataset & $(T . t)^{5}$ & $(T . G)^{5}$ & $(D . O . G . V)^{5}$ & $(O . G)^{5}$ & $(O . T . G)^{5}$ & $(D . O . G)^{5}$ \\
\hline SMEARI & & 2 & $\mathbf{1}$ & & & 3 \\
SMEARII & 3 & & & $\mathbf{1}$ & \\
Ruotsinkylä & $\mathbf{1}$ & & & 3 & & 2 \\
Grandfontaine & $\mathbf{1}$ & 3 & 2 & & & \\
Abreschviller & 3 & & & 2 & & $\mathbf{1}$ \\
Walscheid & $\mathbf{1}$ & & 3 & & & 2 \\
\hline avg rank & 2.33 & 4.67 & 3.67 & 3.67 & 4.33 & 2.33 \\
\hline
\end{tabular}

(b) Ranks - Rate of mature tracheid production (RMTP)

\begin{tabular}{lrrrrrr}
\hline Dataset & $(\text { T.t })^{5}$ & $(T . G)^{5}$ & $(\text { D.O.G.V })^{5}$ & $(O . G)^{5}$ & $(O . T . G)^{5}$ & $(P . T . G)^{5}$ \\
\hline SMEARI & $\mathbf{1}$ & 2 & & & & 3 \\
SMEARII & & 3 & & $\mathbf{1}$ & 2 & \\
Ruotsinkylä & & 3 & & $\mathbf{1}$ & & 2 \\
Grandfontaine & & $\mathbf{1}$ & 3 & & & 2 \\
Abreschviller & & & 2 & 3 & $\mathbf{1}$ & \\
Walscheid & & & 2 & $\mathbf{1}$ & 3 & \\
\hline avg rank & 4.83 & 3.00 & 3.50 & 2.50 & 3.50 & 3.67 \\
\hline
\end{tabular}

altitude gradient in France and along a latitude gradient in Finland. Given environmental data over a time horizon of 10 weeks, the models were able to estimate the weekly rate of tracheid production to within a fraction of a tracheid on average.

A prominent result related to models including the week number, either as such or embedded in the timing of growth variable $O$, indicate that tracheid production and maturation had a regular pattern in all environments, especially in warm sites. Day length follows the week number but the light hours are not totally responsible for the beginning and cessation of growth demonstrated by the applicability of variable $O$, which in general resulted to better performance than solely week number. In this variable, the timing was triggered by the week number but tracheid production activated earlier (or later) if the spring temperature increased early (or late) following thereafter a regular pattern. Regarding the connection between week number and daylight hours, it may be worth noting that day length varies most greatly in the northern sites, and that the northernmost site has constant daylight (24 hours) for several weeks around the summer 
solstice.

The high predictive power of the timing of growth $(O)$ stresses the weather-independent part of new tracheid production even at the most temperature limited site of this study where mean annual temperature is barely over $0^{\circ} \mathrm{C}$. This supports the developmental control of xylogenesis (Cuny and Rathgeber, 2016) and the significance of photoperiod as a driver also there. Seo et al. (2011) studied Scots pine stands in northern Finland and found that $2 / 3$ of radial growth took place within four weeks of midsummer regardless of the beginning of the growing season, probably because cambial activity needs to end early for the produced tracheids to maturate during favorable weather. Also at the warm environment, the maximum rate of tracheid production is reported occurring around the time of maximum day length and not during the warmest period (Rossi et al., 2006; Cuny et al., 2012).

The extended period of tracheid formation in warm climates seen in this study is widely known and reported also by other studies. The earlier onset of new tracheid formation increases the number of tracheids and the maturation of tracheids ends later (Lupi et al., 2010; Rossi et al., 2011). The important role of temperature to determine the rate of tracheid production at several sites in this study (sites 1, 3 and 4) stress the role of air temperature as a regulator for the timing of wood formation and therefore support the earlier findings (Swidrak et al., 2011; Zhai et al., 2012; Jyske et al., 2014). The allocation of assimilated carbon during tracheid production and differentiation requires daily minimum temperatures above $5^{\circ} \mathrm{C}$ (Rossi et al., 2008; Körner, 2015) and possibly explains the strong temperature dependency of the production of mature tracheids at the northernmost site.

Carbohydrates are needed to supply energy for cell division, to generate turgor pressure during cell expansion and to produce polysaccharides during cell-wall formation (Muller et al., 2011). GPP was included in the best combinations predicting the rate of tracheid production at the two northernmost sites. In addition, it was the best predictor alone or it was included in a combination for the production of mature tracheids at all 
sites where the model prediction was acceptable (sites $2-4$, Table $4 \mathrm{~b}$ ). This is in line with Chan et al. (2015) who showed that recently photosynthesized carbon correlates even with daily growth in southern Finland. Also Schiestl-Aalto et al. (2015) found that GPP accelerates the sink activity, i.e., tracheid formation. Zweifel et al. (2010) found a close relationship between stem radius changes and monthly GPP but the relationship was even stronger with net ecosystem production (NEP). Simultaneous photosynthetic production seemed not to limit or accelerate the rate of mature tracheid production in very warm or cold areas of Scots pines but since the model performance was poor in these sites, the drivers for the maturation can not be stated. Nevertheless, GPP is not necessarily limiting growth at temperate sites (Delpierre et al., 2016a). In addition, the model for GPP was parameterized in Southern Finland and it might be less accurate in very cold or warm environments. It must be also taken into consideration that the GPP model was a simplification without e.g., a module for the interannual changes in leaf area, a factor that differs especially between the Northern and the Southern sites of this study. Also the simplified model for soil water dynamics is insufficiently evaluated for different sites but during the study years, the sites did notably not suffer from soil water deficit as suggested also by the model. Low soil moisture most probably influences the inter-annual dynamics of tracheid production and maturation but such conditions did not occur during these study years.

Low tree water status causes reduction in the turgor, enlargement, and division of tracheids, and correspondingly a reduction in diameter increment (Eilmann et al., 2011; Oberhuber et al., 2014). Even if the sites of this study did not suffer from low soil moisture, the northernmost site surprisingly indicated sensitivity to air humidity as VPD was included in the best combination of variables to model the tracheid production (Table 1). It was also relatively competitive even as a single variable. The reason for this remains unknown but possibly the trees there have not prioritized the investments in water transport system that is weaker for evaporative demand than the trees in warmer boreal and temperate environments. This indicates that even if there is water available, the trees 
fail to transport enough water from soil causing a decrease in tree water potential, turgor pressure and optimal rate of tracheid production as found also in temperate trees (Delpierre et al., 2016a). Nevertheless, the studied trees at the different sites varied a little in size and age and thus they have differences for example, in their water storage capacity that might influence further their environmental responses.

It is perhaps worth remarking that the week number corresponds not only directly to day length, but also indirectly to all other variables. Mathematically, temperature can be viewed as a function of the week number: $T(t)=f(t)+\epsilon(t)$ where $f(t)$ is the expected (average) temperature at week $t$ and $\epsilon(t)$ is some quantity reflecting the variation from that expected value. Measuring temperature directly 'adjusts' the function by precision $\epsilon(t)$, but the underlying relationship between week number and temperature $(f(t))$ remains and can be inferred by our data-driven model even without current temperature measurements. All other environmental predictors are similarly related to $t$. This helps explain why appropriate functions of the week number (such as the polynomials and the growth timing function, Eq. (8)) were such powerful predictors. On the other hand, since the decision-tree model (Figure A.8c) ignored $t$, this indicates that temperature still plays a dominant role.

We selected ridge regression as the underlying black box model because it performed best overall in terms of MSE in our initial empirical trials. However, to obtain this performance it was essential to include the polynomial basis functions to obtain a nonlinear decision boundary. The relative benefits of using decision tree models are the inherent non-linearity, leading to fewer variables, and overall they offer some additional interpretation of the underlying process. Both methods have been a staple of the machine learning community for some years.

The idea of trying more complex models is tempting. However, the target attribute (rates of tracheid production and maturation, measured by microcoring) is noisy. This is certainly the main limitation in obtaining any further explanatory power from the model. More frequent measurements over several years could help to improve the model's 
performance and thus give reliable view on the important variables. However, microcores are always taken from a slightly different spot, and the stem is not regular, and therefore it is not possible to eliminate noise completely. A general disadvantage of the black box model is that it requires significant investment in data gathering, and its performance is heavily dependent on both the quality and quantity of data, and the year-to-year variability of a particular site. On the other hand, decision trees models are unstable in the sense that quite different models can be created for relatively small variations in the training data. In particular, obtaining microcore data is labour intensive. With an increasing amount of data available, that disadvantage is being gradually mitigated.

The actual response functions of the main variables, i.e., their exact effect on tracheid production and maturation, is difficult to isolate from the black box models, but the decision tree analysis revealed some of the important periods at each study site. Nevertheless, the detailed understanding on the time horizons, significant periods and causal effect of the important variables to wood formation requires further ecophsysiological studies in the framework of the whole tree water and carbon balance but the current study assists to utilize the main environmental drivers.

\section{Conclusions}

Our novel application of machine learning tools to analyze tracheid production showed that the most important environmental factors affecting the intra-annual dynamics of differentiating and mature tracheid production in Scots pine stems vary under different climates. The formation of new tracheids was partly weather-independent, especially at the warm temperate environments, but GPP 0-10 week earlier played a role in the coolest boreal sites. In sites where mean temperatures were between these outer boundaries, current and previous temperature was the most influential environmental factor. GPP and its history was on average the best single predictor for the rate of mature tracheid production and it was included as a predictor in the most accurate models. Our findings identifying the most important variables for growth can be used in building up 
detailed physiological theories on the production and maturation of Scots pine tracheids in different climates.

\section{Acknowledgements}

This study was supported by the Academy of Finland (257641, 277623), the Academy of Finland Finnish Centre of Excellence Program (272041) and COST action FP1106. We also thank Annikki Mäkelä for the help in GPP modelling.

\section{References}

Babst, F., Bouriaud, O., Papale, D., Gielen, B., Janssens, I.A., Nikinmaa, E., Ibrom, A., Wu, J., Bernhofer, C., Koestner, B., Gruenwald, T., Seufert, G., Ciais, P., Frank, D., 2014. Above-ground woody carbon sequestration measured from tree rings is coherent with net ecosystem productivity at five eddy-covariance sites. New Phytologist 201, 1289-1303. PT: J; TC: 7; UT: WOS:000338510200024.

Chan, T., Hölttä, T., Berninger, F., Mäkinen, H., Nöjd, P., Mencuccini, M., Nikinmaa, E., 2015. Separating water-potential induced swelling and shrinking from measured radial stem variations reveals a cambial growth and osmotic concentration signal. Plant, Cell \& Environment, In Press.

Cuny, H., Rathgeber, C.B., 2016. Xylogenesis: "coniferous trees of temperate forests are listening to the climate tale during the growing season, but only remember the last words!". Plant Physiology doi:\{10.1104/pp.16.00037\}.

Cuny, H.E., Rathgeber, C.B.K., Frank, D., Fonti, P., Fournier, M., 2014. Kinetics of tracheid development explain conifer tree-ring structure. NEW PHYTOLOGIST 203, 1231-1241. doi:\{10.1111/nph. $12871\}$.

Cuny, H.E., Rathgeber, C.B.K., Frank, D., Fonti, P., Makinen, H., Prislan, P., Rossi, S., del Castillo, E.M., Campelo, F., Vavrcik, H., Camarero, J.J., Bryukhanova, M.V., Jyske, T., Gricar, J., Gryc, V., Luis, M.D., Vieira, J., Cufar, K., Kirdyanov, A.V., Oberhuber, W., Treml, V., Huang, J.G., Li, X., Swidrak, I., Deslauriers, A., Liang, E., Nojd, P., Gruber, A., Nabais, C., Morin, H., Krause, C., King, G., Fournier, M., 2015. Woody biomass production lags stem-girth increase by over one month in coniferous forests. Nature Plants 1, 15160. PT: J; TC: 1; UT: WOS:000364417300001.

Cuny, H.E., Rathgeber, C.B.K., Lebourgeois, F., Fortin, M., Fournier, M., 2012. Life strategies in intra-annual dynamics of wood formation: example of three conifer species in a temperate forest in north-east France. TREE PHYSIOLOGY 32, 612-625. doi:\{10.1093/treephys/tps039\}.

Delpierre, N., Berveiller, D., Granda, E., Dufrêne, E., 2016a. Wood phenology, not carbon input, controls the interannual variability of wood growth in a temperate oak forest. New Phytologist 210, 459-470. 
Delpierre, N., Vitasse, Y., Chuine, I., Guillemot, J., Bazot, S., Rutishauser, T., Rathgeber, C.B.K., 2016b. Temperate and boreal forest tree phenology: from organ-scale processes to terrestrial ecosystem models. Annals of Forest Science 73, 5-25. PT: J; TC: 3; UT: WOS:000370753300002.

Eilmann, B., Zweifel, R., Buchmann, N., Pannatier, E.G., Rigling, A., 2011. Drought alters timing, quantity, and quality of wood formation in scots pine. Journal of experimental botany 62, 2763-2771. PT: J; TC: 45; UT: WOS:000290813300024.

Fritts, H.C., 1976. Tree Rings and Climate. Academic Press, New York.

Gea-Izquierdo, G., Bergeron, Y., Huang, J.G., Lapointe-Garant, M.P., Grace, J., Berninger, F., 2014. The relationship between productivity and tree-ring growth in boreal coniferous forests. Boreal Environment Research 19, 363-378. PT: J; TC: 0; UT: WOS:000345732000003.

Hari, P., Kulmala, M., 2005. Station for measuring ecosystem-atmosphere relations (smear ii). Boreal Environment Research 10, 315-322. PT: J; TC: 231; UT: WOS:000233128500001.

Hari, P., Kulmala, M., Pohja, T., Lahti, T., Siivola, E., Palva, L., Aalto, P., Hämeri, K., Vesala, T., Luoma, S., Pulliainen, E., 1994. Air pollution in eastern lapland : challenge for an environmental measurement station. Silva Fennica 28, 29-39.

Hastie, T., Tibshirani, R., Friedman, J., 2001. The Elements of Statistical Learning. Springer Series in Statistics, Springer New York Inc., New York, NY, USA.

Jyske, T., Makinen, H., Kalliokoski, T., Nojd, P., 2014. Intra-annual tracheid production of norway spruce and scots pine across a latitudinal gradient in finland. Agricultural and Forest Meteorology 194, 241-254. PT: J; TC: 1; UT: WOS:000339131400022.

Kalliokoski, T., Reza, M., Jyske, T., Makinen, H., Nojd, P., 2012. Intra-annual tracheid formation of norway spruce provenances in southern finland. Trees-Structure and Function 26, 543-555. PT: J; TC: 3; UT: WOS:000301779200024.

Körner, C., 2015. Paradigm shift in plant growth control. Current opinion in plant biology 25, $107-114$. PT: J; TC: 4; UT: WOS:000359889900015.

Lempereur, M., Martin-StPaul, N.K., Damesin, C., Joffre, R., Ourcival, J.M., Rocheteau, A., Rambal, S., 2015. Growth duration is a better predictor of stem increment than carbon supply in a mediterranean oak forest: implications for assessing forest productivity under climate change. New Phytologist 207, 579-590. PT: J; TC: 2; UT: WOS:000357824400013.

de Lis, G.P., Rossi, S., Vázquez-Ruiz, R.A., Rozas, V., García-González, I., 2015. Do changes in spring phenology affect earlywood vessels? perspective from the xylogenesis monitoring of two sympatric ring-porous oaks. New Phytologist, n/a-n/a.

Lupi, C., Morin, H., Deslauriers, A., Rossi, S., 2010. Xylem phenology and wood production: resolving the chicken-or-egg dilemma. Plant Cell and Environment 33, 1721-1730. PT: J; TC: 50; UT: WOS:000281638000010. 
Mäkelä, A., Pulkkinen, M., Kolari, P., Lagergren, F., Berbigier, P., Lindroth, A., Loustau, D., Nikinmaa, E., Vesala, T., Hari, P., 2008. Developing an empirical model of stand gpp with the lue approach: analysis of eddy covariance data at five contrasting conifer sites in europe. Global Change Biology 14, 92-108. PT: J; TC: 49; UT: WOS:000251415000008.

Muller, B., Pantin, F., Genard, M., Turc, O., Freixes, S., Piques, M., Gibon, Y., 2011. Water deficits uncouple growth from photosynthesis, increase c content, and modify the relationships between c and growth in sink organs. Journal of experimental botany 62, 1715-1729. PT: J; TC: 109; UT: WOS:000288553000002.

Oberhuber, W., Gruber, A., Kofler, W., Swidrak, I., 2014. Radial stem growth in response to microclimate and soil moisture in a drought-prone mixed coniferous forest at an inner alpine site. European Journal of Forest Research 133, 467-479. PT: J; TC: 0; UT: WOS:000333425500006.

Ohtsuka, T., Saigusa, N., Koizumi, H., 2009. On linking multiyear biometric measurements of tree growth with eddy covariance-based net ecosystem production. Global Change Biology 15, 1015-1024. PT: J; UT: WOS:000263752300019.

Partanen, J., Leinonen, I., Repo, T., 2001. Effect of accumulated duration of the light period on bud burst in norway spruce (picea abies) of varying ages. Silva Fennica 35, 111-117. PT: J; UT: WOS:000167986300010.

Peltoniemi, M., Markkanen, T., Harkonen, S., Muukkonen, P., Thum, T., Aalto, T., Makela, A., 2015. Consistent estimates of gross primary production of finnish forests - comparison of estimates of two process models. Boreal Environment Research 20, 196-212. PT: J; TC: 4; UT: WOS:000353934400005.

Plomion, C., Leprovost, G., Stokes, A., 2001. Wood formation in trees. Plant Physiology 127, $1513-1523$. PT: J; TC: 278; UT: WOS:000172824500029.

Ren, P., Rossi, S., Gricar, J., Liang, E., Cufar, K., 2015. Is precipitation a trigger for the onset of xylogenesis in juniperus przewalskii on the north-eastern tibetan plateau? Annals of Botany 115, 629-639. PT: J; TC: 3; UT: WOS:000354066600007.

Rossi, S., Anfodillo, T., Cufar, K., Cuny, H.E., Deslauriers, A., Fonti, P., Frank, D., Gricar, J., Gruber, A., King, G.M., Krause, C., Morin, H., Oberhuber, W., Prislan, P., Rathgeber, C.B.K., 2013. A meta-analysis of cambium phenology and growth: linear and non-linear patterns in conifers of the northern hemisphere. Annals of Botany 112, 1911-1920. PT: J; TC: 5; UT: WOS:000327717100021. Rossi, S., Deslauriers, A., Anfodillo, T., Morin, H., Saracino, A., Motta, R., Borghetti, M., 2006. Conifers in cold environments synchronize maximum growth rate of tree-ring formation with day length. New Phytologist 170, 301-310. PT: J; TC: 132; UT: WOS:000236248200012.

Rossi, S., Deslauriers, A., Gricar, J., Seo, J.W., Rathgeber, C.B.K., Anfodillo, T., Morin, H., Levanic, T., Oven, P., Jalkanen, R., 2008. Critical temperatures for xylogenesis in conifers of cold climates. Global Ecology and Biogeography 17, 696-707. PT: J; TC: 110; UT: WOS:000260114200003. 
Rossi, S., Morin, H., Deslauriers, A., Plourde, P.Y., 2011. Predicting xylem phenology in black spruce under climate warming. Global Change Biology 17, 614-625. PT: J; TC: 26; UT: WOS:000284851500049. Schiestl-Aalto, P., Kulmala, L., Mäkinen, H., Nikinmaa, E., Mäkela, A., 2015. Cassia - a dynamic model for predicting intra-annual sink demand and interannual growth variation in scots pine. New Phytologist 206, 647-659. PT: J; TC: 0; UT: WOS:000351742300019.

Seo, J.W., Eckstein, D., Jalkanen, R., Rickebusch, S., Schmitt, U., 2008. Estimating the onset of cambial activity in scots pine in northern finland by means of the heat-sum approach. Tree physiology 28 , 105-112. PT: J; TC: 56; UT: WOS:000252571800012.

Seo, J.W., Eckstein, D., Jalkanen, R., Schmitt, U., 2011. Climatic control of intra- and inter-annual wood-formation dynamics of scots pine in northern finland. Environmental and experimental botany 72, 422-431. PT: J; SI: SI; TC: 19; UT: WOS:000293810300011.

Swidrak, I., Gruber, A., Kofler, W., Oberhuber, W., 2011. Effects of environmental conditions on onset of xylem growth in pinus sylvestris under drought. Tree physiology 31, 483-493. PT: J; NR: 71; TC: 19; J9: TREE PHYSIOL; PG: 11; GA: 780XF; UT: WOS:000291893600003.

Vaganov, E.A., Hughes, M.K., Shashkin, A.V., 2006. Growth Dynamics of Conifer Tree Rings. volume XIV. Springer Heidelberg.

Zhai, L., Bergeron, Y., Huang, J.G., Berninger, F., 2012. Variation in intra-annual wood formation, and foliage and shoot development of three major canadian boreal tree species. American Journal of Botany 99, 827-837. PT: J; TC: 6; UT: WOS:000303665300015.

Zweifel, R., Eugster, W., Etzold, S., Dobbertin, M., Buchmann, N., Haesler, R., 2010. Link between continuous stem radius changes and net ecosystem productivity of a subalpine norway spruce forest in the swiss alps. New Phytologist 187, 819-830. PT: J; TC: 18; UT: WOS:000280122500023.

\section{Appendix A. Individual MSE Results}


Table A.6: Total error accumulated over three years.

(a) MSE - Individual variables - Tracheid production (RDTP)

\begin{tabular}{lrrrrrrr}
\hline Dataset & $(t)^{5}$ & $(T)^{5}$ & $(S)^{5}$ & $(V)^{5}$ & $(G)^{5}$ & $D$ & $O$ \\
\hline SMEARI & $0.791(5)$ & $0.750(4)$ & $1.939(7)$ & $0.840(6)$ & $0.564(2)$ & $0.516(1)$ & $0.666(3)$ \\
SMEARII & $0.711(1)$ & $0.736(3)$ & $1.867(7)$ & $1.166(6)$ & $0.759(4)$ & $0.816(5)$ & $0.718(2)$ \\
Ruotsinkylä & $1.619(2)$ & $1.607(1)$ & $2.863(7)$ & $2.340(6)$ & $2.138(5)$ & $1.821(4)$ & $1.697(3)$ \\
Grandfontaine & $0.135(4)$ & $0.082(1)$ & $0.439(7)$ & $0.181(6)$ & $0.174(5)$ & $0.113(2)$ & $0.115(3)$ \\
Abreschviller & $0.227(2)$ & $0.261(3)$ & $0.935(7)$ & $0.372(6)$ & $0.278(4)$ & $0.290(5)$ & $0.207(1)$ \\
Walscheid & $1.089(2)$ & $1.325(3)$ & $2.883(7)$ & $1.490(5)$ & $1.561(6)$ & $1.476(4)$ & $1.087(1)$ \\
\hline avg rank & 2.67 & 2.50 & 7.00 & 5.83 & 4.33 & 3.50 & 2.17 \\
\hline
\end{tabular}

(b) MSE - Individual variables - Mature tracheid production (RMTP)

\begin{tabular}{lrrrrrrr}
\hline Dataset & $(t)^{5}$ & $(T)^{5}$ & $(S)^{5}$ & $(V)^{5}$ & $(G)^{5}$ & $D$ & $O$ \\
\hline SMEARI & $0.977(4)$ & $0.880(3)$ & $1.935(7)$ & $1.050(5)$ & $1.096(6)$ & $0.784(1)$ & $0.866(2)$ \\
SMEARII & $0.597(4)$ & $0.639(5)$ & $1.239(7)$ & $1.095(6)$ & $0.445(1)$ & $0.567(2)$ & $0.596(3)$ \\
Ruotsinkylä & $2.244(2)$ & $3.509(6)$ & $2.479(4)$ & $3.971(7)$ & $2.170(1)$ & $2.903(5)$ & $2.275(3)$ \\
Grandfontaine & $0.226(4)$ & $0.229(5)$ & $0.422(7)$ & $0.273(6)$ & $0.188(1)$ & $0.212(2)$ & $0.216(3)$ \\
Abreschviller & $0.265(1)$ & $0.285(3)$ & $0.675(7)$ & $0.285(4)$ & $0.298(6)$ & $0.286(5)$ & $0.284(2)$ \\
Walscheid & $1.954(1)$ & $2.556(5)$ & $2.886(7)$ & $2.857(6)$ & $2.325(3)$ & $2.429(4)$ & $1.978(2)$ \\
\hline avg rank & 2.67 & 4.50 & 6.50 & 5.67 & 3.00 & 3.17 & 2.50 \\
\hline
\end{tabular}

(c) MSE - Combinations of variables - RDTP

\begin{tabular}{lrrrrrr}
\hline Dataset & $(T . t)^{5}$ & $(T . G)^{5}$ & $(\text { D.O.G.V })^{5}$ & $(O . G)^{5}$ & $(O . T . G)^{5}$ & $(\text { D.O.G })^{5}$ \\
\hline SMEARI & $0.755(5)$ & $0.573(2)$ & $0.131(1)$ & $0.821(6)$ & $0.631(4)$ & $0.604(3)$ \\
SMEARII & $0.738(3)$ & $0.949(6)$ & $0.808(5)$ & $0.625(1)$ & $0.745(4)$ & $0.657(2)$ \\
Ruotsinkylä & $1.606(1)$ & $2.142(6)$ & $2.059(5)$ & $1.880(3)$ & $1.925(4)$ & $1.862(2)$ \\
Grandfontaine & $0.086(1)$ & $0.104(3)$ & $0.091(2)$ & $0.139(6)$ & $0.114(5)$ & $0.105(4)$ \\
Abreschviller & $0.264(3)$ & $0.281(5)$ & $0.299(6)$ & $0.256(2)$ & $0.272(4)$ & $0.238(1)$ \\
Walscheid & $1.325(1)$ & $1.424(6)$ & $1.329(3)$ & $1.332(4)$ & $1.339(5)$ & $1.328(2)$ \\
\hline avg val. & 0.80 & 0.91 & 0.79 & 0.84 & 0.84 & 0.80 \\
avg rank & 2.33 & 4.67 & 3.67 & 3.67 & 4.33 & 2.33 \\
\hline
\end{tabular}

(d) MSE - Combinations of variables - RMTP

\begin{tabular}{lrrrrrr}
\hline Dataset & $(T . t)^{5}$ & $(T . G)^{5}$ & $(\text { D.O.G.V })^{5}$ & $(O . G)^{5}$ & $(O . T . G)^{5}$ & $(P . T . G)^{5}$ \\
\hline SMEARI & $0.874(1)$ & $0.882(2)$ & $1.047(5)$ & $0.936(4)$ & $1.175(6)$ & $0.897(3)$ \\
SMEARII & $0.638(6)$ & $0.530(3)$ & $0.630(5)$ & $0.396(1)$ & $0.470(2)$ & $0.536(4)$ \\
Ruotsinkylä & $3.489(6)$ & $2.973(3)$ & $3.370(4)$ & $2.779(1)$ & $3.449(5)$ & $2.932(2)$ \\
Grandfontaine & $0.225(6)$ & $0.177(1)$ & $0.185(3)$ & $0.188(5)$ & $0.185(4)$ & $0.178(2)$ \\
Abreschviller & $0.288(6)$ & $0.284(4)$ & $0.254(2)$ & $0.256(3)$ & $0.252(1)$ & $0.286(5)$ \\
Walscheid & $2.566(4)$ & $2.629(5)$ & $2.517(2)$ & $2.346(1)$ & $2.526(3)$ & $2.639(6)$ \\
\hline avg val. & 1.35 & 1.25 & 1.33 & 1.15 & 1.34 & 1.24 \\
avg rank & 4.83 & 3.00 & 3.50 & 2.50 & 3.50 & 3.67 \\
\hline
\end{tabular}




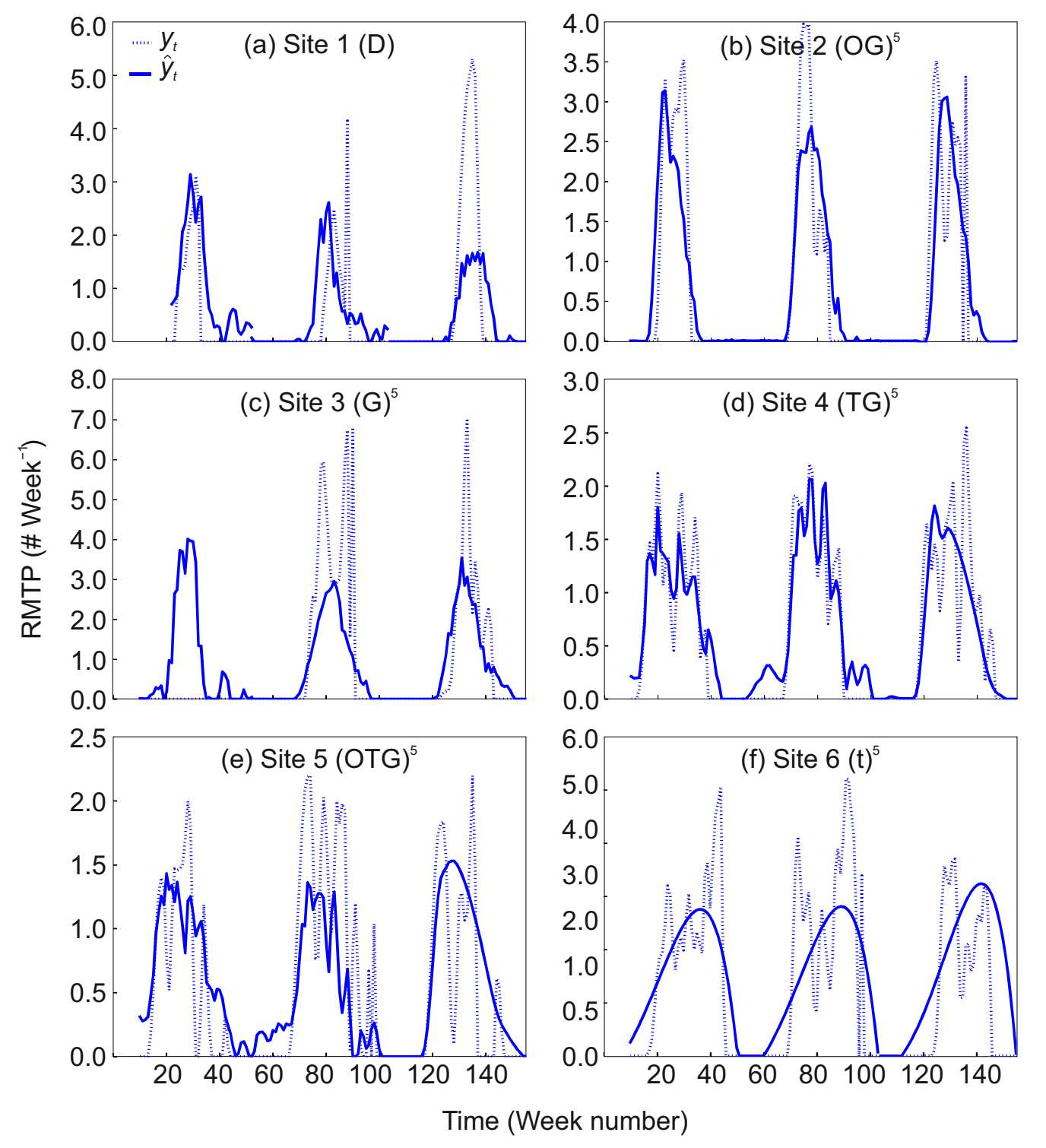

Figure A.7: Measured $(y)$ and estimated $\left(\hat{y}_{t}\right)$ RMTP (vertical axis) of the black box model for all years tested. The variables of the model were those which obtained the lowest MSE values (Table A.6) (each site modeled separately). No measurements for Ruotsinkylä available for the first year. 
Table A.7: Parameters of the GPP model. In addition, we used soil depth $\left(L_{S}\right)$ of $470 \mathrm{~mm}$ for the Boreal (Finnish) sites and of $1000 \mathrm{~mm}$ for the Temperate (French) ones. The temperature measured on January 1st was used as the priori estimate for the state of temperature acclimation $(X)$.The model, modifiers and parameters are introduced in detail by Peltoniemi et al. (2015).

\begin{tabular}{|c|c|c|c|}
\hline & symbol & value & unit \\
\hline $\begin{array}{l}\text { Coefficient for temperature dependence of } \\
\text { snowmelt rate }\end{array}$ & $m$ & 2.5 & ${ }^{\circ} C^{-1} d^{-1}$ \\
\hline $\begin{array}{l}\text { Delay parameter for the response of temperature } \\
\text { acclimation state to the changes in ambient tem- } \\
\text { perature }\end{array}$ & $\tau$ & 11.7 & - \\
\hline Delay parameter of drainage & $\tau_{F}$ & 1 & - \\
\hline Effective field capacity & $\theta_{F C}$ & 0.448 & $\mathrm{~mm}$ \\
\hline Effective wilting point & $\theta_{W P}$ & 0.118 & $m m$ \\
\hline Evaporation parameter & $\chi$ & 0.0551 & $m m m o l^{-1}$ \\
\hline $\begin{array}{l}\text { Light modifier parameter for saturation with ir- } \\
\text { radiance }\end{array}$ & $\gamma$ & 0.0351 & $m o l^{-1} m^{-2}$ \\
\hline Potential light use efficiency & $\beta_{P}$ & 0.777 & $g C m o l^{-1} m^{-2}$ \\
\hline Sensitivity parameter of $f_{D}$ to VPD & $\kappa$ & -0.174 & $k P a^{-1}$ \\
\hline $\begin{array}{l}\text { Threshold above which the state of acclimation } \\
\text { increases }\end{array}$ & $X_{0}$ & -2.6 & ${ }^{\circ} \mathrm{C}$ \\
\hline $\begin{array}{l}\text { Threshold at which the acclimation modifier } \\
\text { reaches its maximum }\end{array}$ & $S_{\max }$ & 17.5 & ${ }^{\circ} \mathrm{C}$ \\
\hline Threshold for $\mathrm{W}$ effect on $\mathrm{P}$ in modifier $f_{W, P}$ & $\rho_{P}$ & 0.422 & - \\
\hline $\begin{array}{l}\text { Threshold for W effect on evaporation in modifier } \\
f_{W, E}\end{array}$ & $\rho_{E}$ & 0.717 & - \\
\hline $\begin{array}{l}\text { Fraction of absorbed photosynthetically active } \\
\text { radiation }\end{array}$ & $f_{A P A R}$ & 0.81 & - \\
\hline Transpiration parameter & $\beta_{E}$ & 0.4 & $\left(g C m^{-2}\right)^{-1}$ \\
\hline Parameter adjusting transpiration with VPD & $\alpha_{E}$ & 0.822 & - \\
\hline
\end{tabular}


(a) Site 1 (Smear I): D.O.G.V $O(a)[-3] \leq 0.85$
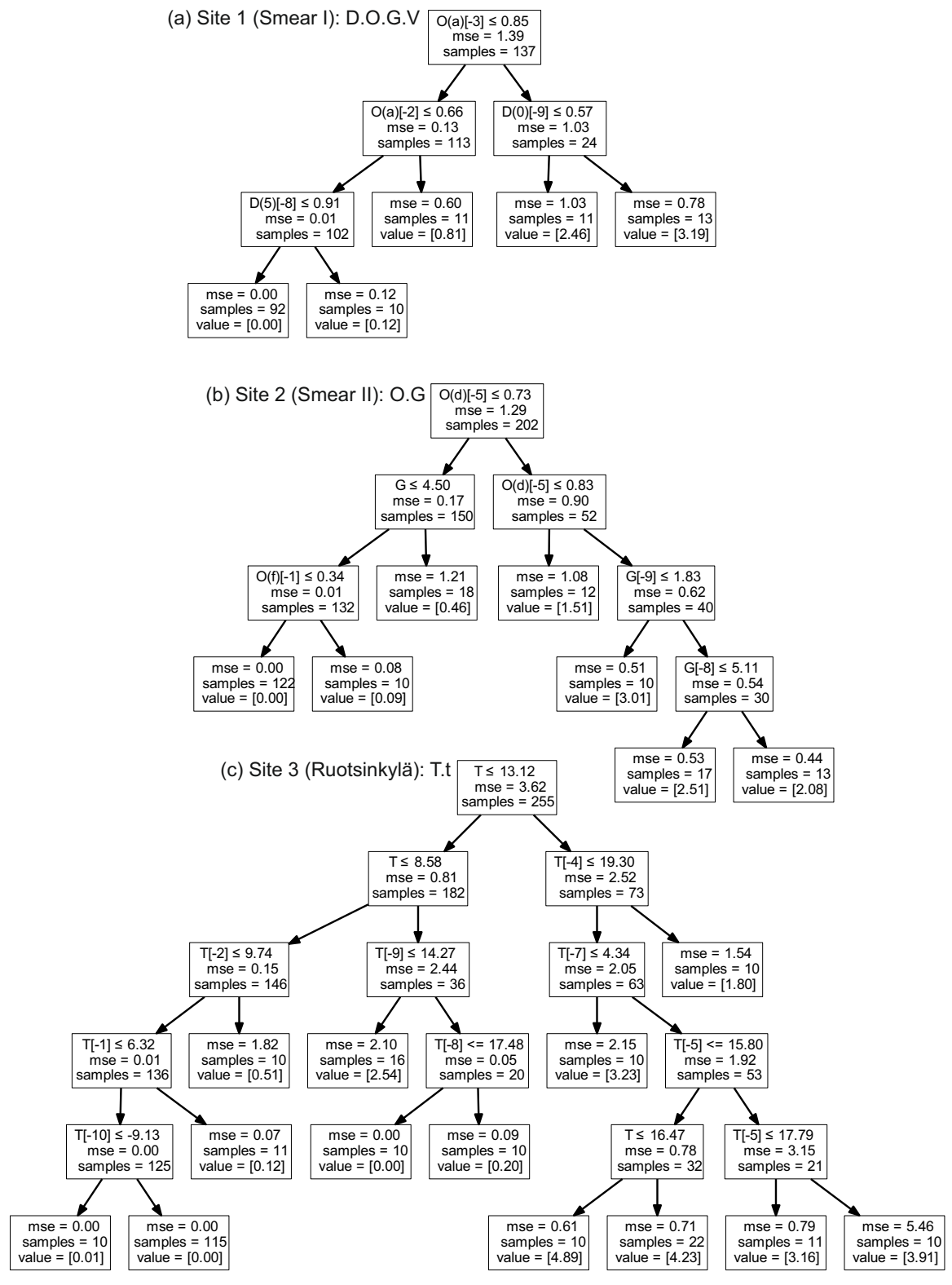

Figure A.8: Decision-tree models for the rate of tracheid production (RDTP) in the Finnish sites (Sites 1-3) trained on all years, pruned to a maximum depth of 5 and minimum of 10 samples per leaf. The higher predictors are in the graph the better predictors the more important they are. The value indicates the predicted value (in number of tracheids); (x) indicates one of the different parameterizations $\left(x={ }^{\circ} C\right.$ in the case of $D(x))$; [- $\mathrm{t}$ ] signifies that the measurement comes from $t$ weeks in the past. The instructions to interpret the figure is given in the section 2.7 . 


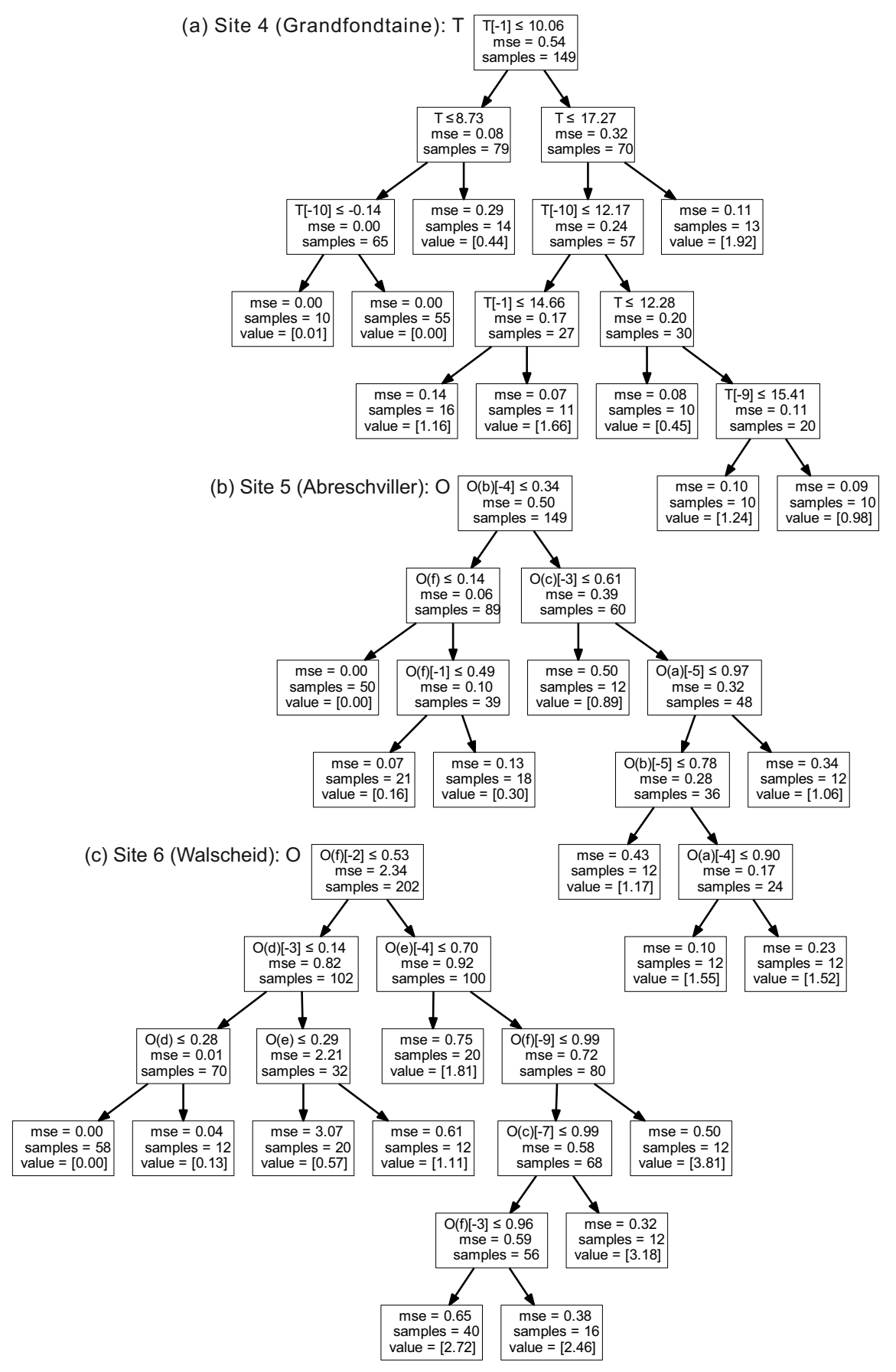

Figure A.9: Decision-tree models for the rate of tracheid production (RDTP) as in Figure A.8 but for the French sites (4-6)). 
(a) Site 1 (Smear I): D D(5)[-3] $\leq 0.77$
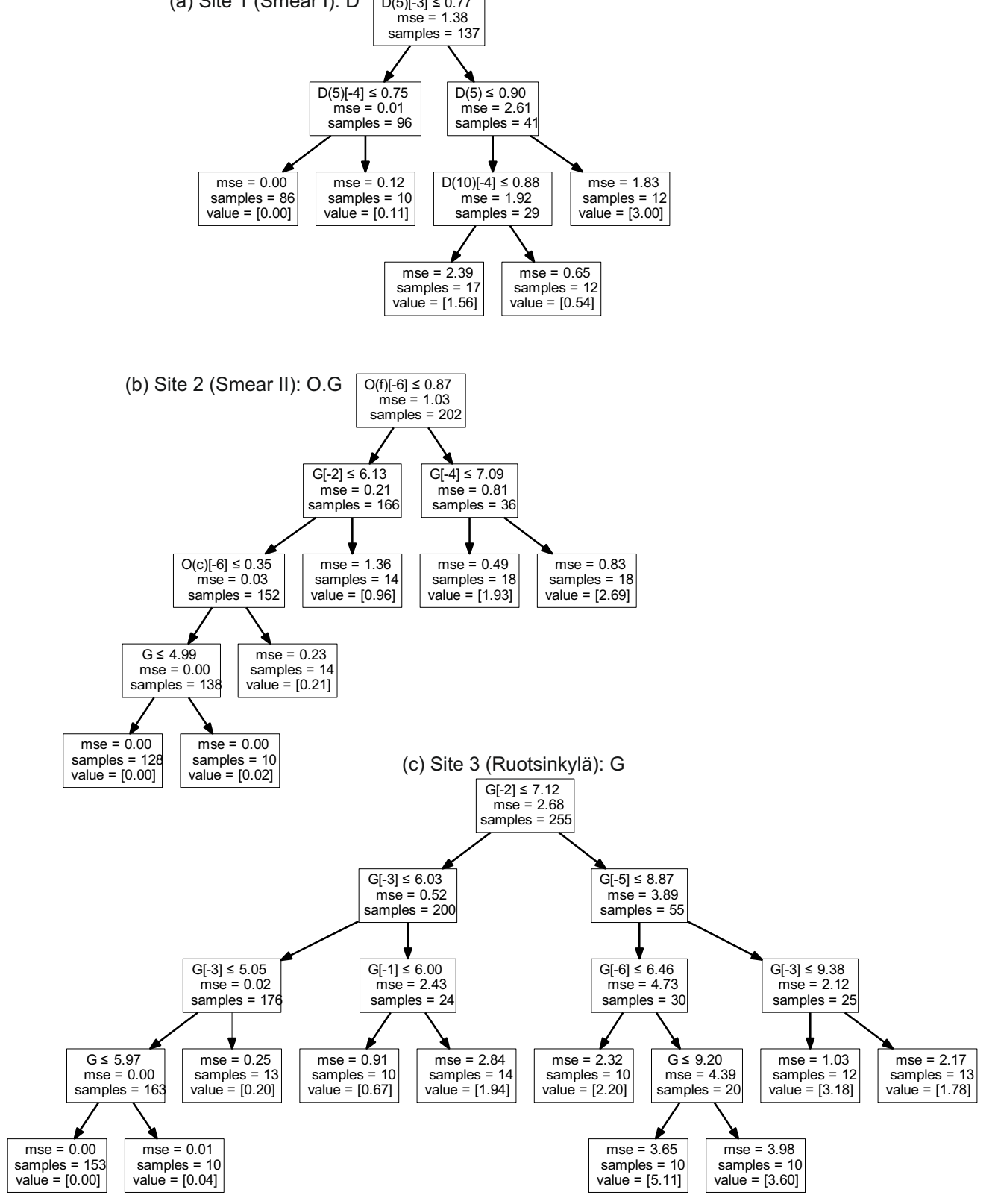

Figure A.10: As in Figure A.8 but for the rate of mature tracheid production (RMTP) for the Finnish sites (1-3). 
(a) Site 4 (Grandfondtaine): T.G $\mathrm{G}[-5] \leq 6.17$

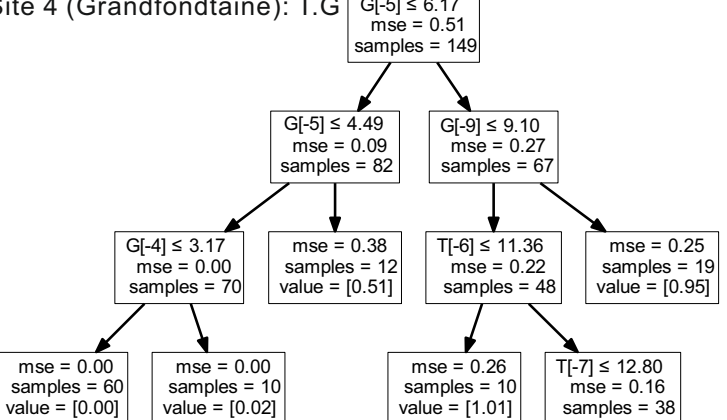

(b) Site 5 (Abreschviller): O.T.G $\begin{gathered}\text { O(d) }[-10] \leq 0.53 \\ \mathrm{mse}=0.49\end{gathered}$
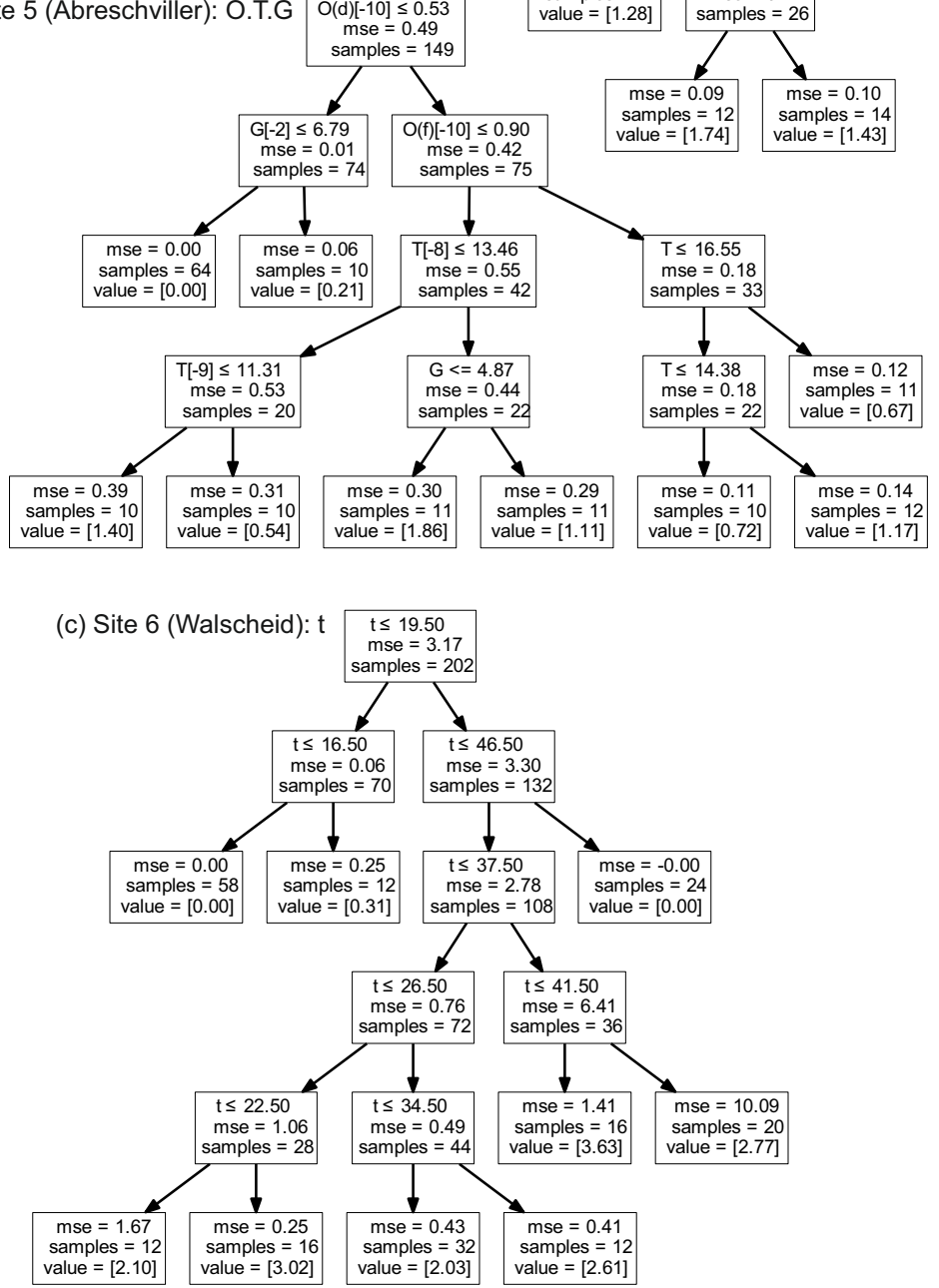

Figure A.11: As in Figure A.8 but for the rate of mature tracheid production (RMTP) for the French sites (4-6). 